\title{
The Effect of Moisture Content Variation on the Bioremediation of Hydrocarbon Contaminated Soils: Modeling and Experimental Investigation
}

\author{
Fatemeh Bahmani ${ }^{1 *}$, Seyed Ahmad Ataei ${ }^{1}$ and Mohammad Ali Mikaili ${ }^{2}$ \\ ${ }^{1}$ Department of Chemical Engineering, Shahid Bahonar University of Kerman, Kerman, Iran \\ ${ }^{2}$ Department of Civil and Environmental Engineering, Amirkabir University of Technology, Tehran, Iran
}

"Corresponding author: Fatemeh Bahmani, Department of Chemical Engineering, Shahid Bahonar University of Kerman, Kerman, Iran, Tel: 989171870672; E-mail: fatemeh.bahmani842@gmail.com

Received date: April 02, 2018; Accepted date: April 12, 2018; Published date: April 18, 2018

Copyright: @ 2018 Bahmani F, et al. This is an open-access article distributed under the terms of the Creative Commons Attribution License, which permits unrestricted use, distribution, and reproduction in any medium, provided the original author and source are credited.

\begin{abstract}
This study reports the effect of water content variation on the rate of Total Petroleum Hydrocarbon (TPH) removal from a contaminated soil. For this purpose, four samples of the soil with weight of $2 \mathrm{~kg}$ were placed in identical beakers. The initial TPH content of the soil sample was $60 \mathrm{~g} \mathrm{~kg}^{-1}$, and the initial moisture content of the samples was adjusted to $60 \%$ of the field water holding capacity of the soil. The process of bioremediation was started by nutrient addition and inoculation of TPH degrading microorganisms to the soil. The water content of the samples was restored to the initial value intermittently by water addition. The frequency of water restoration, however, was different for the samples. For the first sample water was restored every two days, for the second sample every four days, for the third sample every 8 days, and finally for the fourth sample every 12 days. The process was continued for 90 days. Microbial counting showed that the number of total heterotrophic bacterial, and TPH degraders were increased significantly in all soil samples. Quantification of TPH residual in soil showed significant difference between the soil samples. For the soil sample with 2 day water restoration pattern, the TPH content decreased from 60 to $18.6 \mathrm{~g} \mathrm{~kg}^{-1}$. For other samples the degradation was significantly lower. For the soil sample with 12 day water restoration pattern the TPH content decreased from 60 to $42 \mathrm{~g} \mathrm{~kg}^{-1}$ during the process. A model was developed to predict moisture variation and TPH removal form the soil as a function of time. The model predicted the experimental reasonably well.
\end{abstract}

Keywords: Total petroleum hydrocarbon; Biodegradation; Soil; Moisture content; Modeling

\section{Introduction}

Contamination of soil with hydrocarbons has become one of the most serious environmental problems. Accidental spillage, improper disposal of oily sludge, and leakage from storage tanks are some causes of soil contamination. The presence of hydrocarbons in soil has adverse environmental consequences. Pollutants damage agricultural productivity of the soil, and can find their ways to subsurface waters [1]. Exploiting the capability of microorganisms to degrade pollutants in soil is a promising strategy. Many microbial species can use hydrocarbons as the source of carbon and energy at the presence of a suitable electron acceptor (usually oxygen), and sufficient moisture and nutrients [2].

Natural attenuation of hydrocarbons in soil can be very long and therefore intervention is required in order to accelerate natural degradation of hydrocarbons in soil. Various ways have been examined to enhance the rate of bioremediation in soil. Supplementing nutrients (bio-stimulation), microorganisms (bio-augmentation) and/or a combination of both have been recommended to accelerate the process [3]. Aeration and adding bulking agents are other ways of enhancing the bioremediation rate $[4,5]$.

Moisture content of soil plays an important role in soil bioremediation. Sufficient water should be presented in soil to support microbial activities. Limited amounts of water in soil inhibit microbial activity, while excessive water may fill pores in soil and create resistance against the diffusion of oxygen toward microorganisms. Thus, providing an optimal value of water content is very important in soil for bioremediation. Previous research work has shown that the microbial activity is maximum in soil when the water content of the soil is $60 \%$ of its water holding capacity [6]. Water evaporation from soil is unavoidable during bioremediation. Deviation of the soil water content from its optimum value affects bioremediation significantly. The aim of this study is to evaluate the effect of water content change on the amount of gasoil removal from a contaminated soil.

\section{Materials and Methods}

\section{Soil}

A sandy clay soil was used in the experiments. It consisted of $35 \%$ clay, $45 \%$ fine sand, and $20 \%$ silt. The nitrogen and phosphorus content of the soil were $360 \mathrm{mg} \mathrm{kg}^{-1}$ and $102 \mathrm{mg} \mathrm{kg}^{-1}$, respectively. Soil $\mathrm{pH}$ was 7.8. The water holding capacity of the soil was determined to be $0.3 \mathrm{~g}$ $\mathrm{kg}^{-1}$.

\section{Microbial inoculation}

An unidentified microbial culture with the ability of growing on gasoil as the sole source of carbon and energy was inoculated to the soil. 
Page 2 of 6

\section{Bioremediation}

The soil was contaminated with gasoil $\left(10 \% \mathrm{w} \mathrm{w}^{-1}\right)$, and spread on the floor for one week. After vaporization of the volatile fraction of the gasoil, the soil was supplemented with ammonium sulfate and potassium hydrogen phosphate to reach the approximate $\mathrm{C} / \mathrm{N} / \mathrm{P}$ ratio of $100 / 10 / 1.25 \mathrm{~mL} \mathrm{~kg}^{-1}$ of a trace element solution was added to the soil. The composition of the trace element solution was $\left(\mathrm{g} \mathrm{L}^{-1}\right): \mathrm{ZnSO}_{4}$ : 0.068, $\mathrm{H}_{3} \mathrm{BO}_{3}: 0.015, \mathrm{CuSO}_{4}: 0.006, \mathrm{NaMoO}_{4}: 0.07, \mathrm{MnCl}_{2}: 0.04$. Bioremediation experiments were performed in five identical cylindrical beakers. Each beaker was filled with $2 \mathrm{~kg}$ of the contaminated soil, and inoculated with $25 \mathrm{~mL}$ of the microbial culture. Water was added to the level of $60 \%$ of the soil water holding capacity $\left(180 \mathrm{~g} \mathrm{~kg}^{-1}\right)$. The beakers were kept under ambient temperature. The temperature varied between 25 and $30^{\circ} \mathrm{C}$. The changes in water content $(\theta)$ of each beaker were determined at specified time intervals and restored to its initial value of $\theta_{\text {Init }}=0.28 \mathrm{~m}^{3} \mathrm{~m}^{-3}$.

The time interval was different for each beaker. For the first beaker (P1) the time interval was considered 2 days. For the second (P2), third (P3), and forth (P4) beakers, the time intervals were 4,8 and 12 days, respectively. The fifth beaker (P5) served as the control without microbial inoculation. The moisture content of soil in this beaker was restored every 2 days. After water replenishment at each time interval, the soil in beakers was manually blended. Each column had a duplicate.

\section{Gasoil extraction from the soil}

The bioremediation process continued for 90 days. On days 0,30 , 60 , and 90 , the soil contents of the beakers were thoroughly blended, and $2 \mathrm{~g}$ soil from each beaker was collected for gasoil extraction. The extraction was performed in a Soxhlet extractor using $280 \mathrm{~mL}$ chloroform as the extractant for 12 hours. After extraction, chloroform was evaporated and separated from gasoil under slight vacuum. All samples were extracted under similar conditions.

\section{GC analysis for TPH quantification}

The amount of TPH was quantified by GC analysis of extracted samples. The gas chromatograph was equipped with a $5 \%$ MetildicareRtx-5 MS capillary column. Helium served as the carrier gas with the flow rate of $10 \mathrm{~mL} \mathrm{~min}{ }^{-1}$. The initial column temperature was $50^{\circ} \mathrm{C}$. The temperature increased at the rate of $30^{\circ} \mathrm{C} \mathrm{min}{ }^{-1}$ to the final temperature of $300^{\circ} \mathrm{C}$ and was maintained at this temperature for $1 \mathrm{~min}$. The injection port and detector temperatures were $250^{\circ} \mathrm{C}$ and $300^{\circ} \mathrm{C}$, respectively. All extracted samples were dissolved in chloroform and injected to the gas chromatograph under the same conditions. The biodegradation was quantified by comparing the total surface area of the chromatogram of the samples with the total surface area of the chromatogram of the sample extracted on day zero.

\section{Quantification of the microbial growth}

The growth of hydrocarbon degrading microorganisms was quantified by culturing soil samples on Bushnell-Hass agar. On days 0 (before inoculation), $18,38,58$ and 80 , a soil suspension was prepared by mixing $5 \mathrm{~g}$ of the soil in each beaker with $50 \mathrm{~mL}$ distilled water. A 10 -fold serial dilution was carried out. The suspensions were inoculated to Bushnell-Hass agar containing plates. The plates were incubated at $30^{\circ} \mathrm{C}$ for 4 days. The number of colonies was counted by a standard procedure [7].

\section{Model development}

Following assumptions were used to model the process of soil bioremediation:

The soil is a pseudo-homogenous phase.

The soil is mixed regularly and therefore spatial variation is ignored.

The rate of water evaporation from the soil surface is proportional to the moisture content of the soil at the surface. Eq. 1 was used to estimate the water content variation in the soil.

The lower boundary condition is controlled by free drainage and the upper boundary condition by evaporation rate.

The rate of TPH biodegradation is a function of TPH concentration in the soil and follows a first order rate equation.

The constant in rate equation (Eq. 2) is affected by the soil moisture content. Below a specific value of moisture, the constant is zero, and above an optimum value the constant holds a maximum value. Between these two critical values the constant is affected linearly by the moisture content of the soil.

Water content and TPH concentration are the only factors affecting the biodegradation rate.

Based on the above assumptions the governing equations are obtained as follows:

$$
\begin{aligned}
& v \mathrm{~d} \theta / \mathrm{dt}=\mathrm{q}_{\text {in }}-\mathrm{q}_{\text {out }}(1) \\
& \mathrm{q}_{\text {in }}=0(2) \\
& \mathrm{q}_{\text {out }}=\mathrm{AP}_{\mathrm{ET}}\left(\theta-\theta_{\mathrm{r}} / \theta_{\text {sat }}-\theta_{\mathrm{r}}\right)(3)
\end{aligned}
$$

Where, $v=$ volume of the beaker, $\theta=$ water content, $q=$ volumetric flow rate of water, $\mathrm{A}$ =surface of the beaker, $\mathrm{P}_{\mathrm{ET}}=$ potential evaporation which was constant during the experiment at $0.00495 \mathrm{~m}$ day-1, $\theta_{\mathrm{r}}=$ residual water content, $\theta_{\text {sat }}=$ saturation water content.

For the sandy clay soil texture:

$\theta_{\mathrm{r}}=0.07, \theta_{\text {sat }}=0.44[8]$

Mass balance equation for TPH in the soil:

$\mathrm{dC}_{\mathrm{TPH}} / \mathrm{dt}=\mathrm{k}_{\mathrm{B}} \mathrm{f}(\theta) \mathrm{C}_{\mathrm{TPH}}(4)$

$\mathrm{C}_{\mathrm{TPH}}(0)=\mathrm{C}_{\mathrm{TPH} 0}(5)$

Where, $\mathrm{C}_{\mathrm{TPH}}=$ concentration of gasoil in the soil, $\mathrm{k}_{\mathrm{B}}=$ adjustable parameter, $\mathrm{f}(\theta)=$ an empirical relation which has been defined in Eq 6:

$$
\begin{aligned}
& \mathrm{f}(\theta)=\left(\theta-\theta_{\mathrm{r}} / \theta_{\text {sat }}-\theta_{\mathrm{r}}\right) \theta_{\mathrm{r}} \leq \theta \leq \theta_{\text {sat }}(6) \\
& \mathrm{f}(\theta)=1 \theta>\theta_{\text {sat }} \\
& \mathrm{f}(\theta)=0 \quad \theta<\theta_{\mathrm{r}}
\end{aligned}
$$

The set of equations were solved numerically, and the data from the beaker with 12-day water restoration interval were used to adjust $\mathrm{k}_{\mathrm{B}}$. The model was verified by the data from other beakers.

\section{Results and Discussion}

\section{Microbial population}

The results of microbial count on Bushnell-Huss agar at time zero showed the microbial population of $2 \times 10^{5} \mathrm{cfu} \mathrm{kg}^{-1}$. Successful biodegradation of soil requires microbial population to be at least $10^{6}$ 
Page 3 of 6

$\mathrm{cfu} \mathrm{kg}^{-1}$ [9]. Therefore, soil needs bio-augmentation. Figure 1 shows changes in hydrocarbon degrading microbial populations during the experiment. In all soil samples the microbial population increased considerably during the process. The rate of increase in population, however, was higher in beakers with more frequent water restoration.

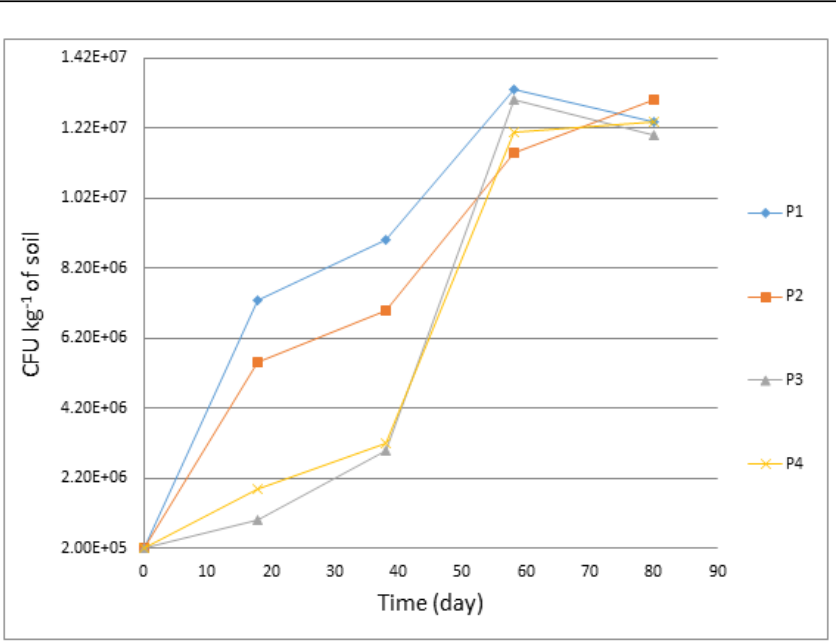

Figure 1: Microbial count on Bushnell-Huss agar during the bioremediation process.

\section{TPH degradation}

Evaporation caused $40 \pm 0.730 \%$ removal of gasoil during one week when the soil was spread on the floor before bioremediation. Therefore, the TPH content of the soil samples was $60 \mathrm{~g} \mathrm{~kg}^{-1}$ at the beginning of the bioremediation process. The results of TPH biodegradation are shown in Figure 2. The best result was for the sample with two day water restoration interval. In this sample the TPH content decreased to $18.6 \mathrm{~g} \mathrm{~kg}^{-1}$ during 90 days of the process. Water content monitoring for this sample showed its water content decreased from 0.288 to $0.251 \mathrm{~m}^{3} \mathrm{~m}^{-3} \pm 0.29 \%$ in two days. For the sample with four day water restoration interval (P2), the TPH content decreased to $22.8 \mathrm{~g} \mathrm{~kg}^{-1}$, and the soil water content varied between 0.288 to 0.216 $\mathrm{m}^{3} \mathrm{~m}^{-3} \pm 0.62 \%$ during the four day intervals. For the sample with 8 day water restoration period (P3), the TPH content of the soil decreased to $28.8 \mathrm{~g} \mathrm{~kg}^{-1}$, and the soil water content varied between 0.288 to $0.187 \mathrm{~m}^{3} \mathrm{~m}^{-3} \pm 0.21 \%$ during the 8 day intervals, and finally for the sample with 12-day water restoration intervals, the TPH content decreased to $42 \mathrm{~g} \mathrm{~kg}^{-1}$, and the soil water content varied between 0.288 and $0.158 \mathrm{~m}^{3} \mathrm{~m}^{-3} \pm 0.56 \%$ during the 12 -day intervals. The results of this study emphasize the importance of keeping the soil water content near the optimum value. Large fluctuations in the soil water content negatively affect the rate of TPH biodegradation in soil. For the sample with no microbial inoculation and 2-day water restoration interval (P5) the TPH degradation was considerably lower than sample (P1) with identical water restoration pattern but with microbial inoculation [10-12]. Therefore, inoculation of TPH degrading microorganisms accelerates the rate of TPH degradation considerably.

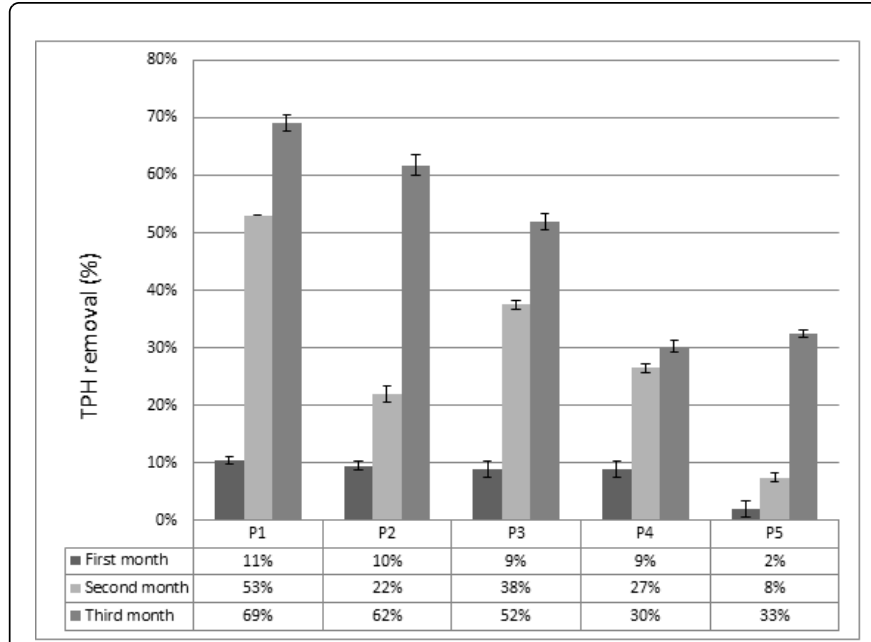

Figure 2: Gasoil biodegradation in the soil after three months.

Figure 3 shows the GC chromatogram of the extracted TPH form the soil sample for initial gasoil. Figures 4-6 show the chromatograms for the extracted TPH at the beginning of the process and at the end for the samples with 2 and 12-day water restoration intervals. The first peak in these chromatograms represents the extractant for TPH (chloroform) $[13,14]$. The initial gasoil chromatogram shows many peaks. The chromatogram for the extracted TPH from the soil at the beginning of the process shows considerably lower number of peaks compared to the initial gasoil due to the evaporation of light components of the gasoil. The chromatogram of the extracted TPH from the soil at the end of the process shows even lower number of peaks indicating degradation of the gasoil components during the bioremediation process.

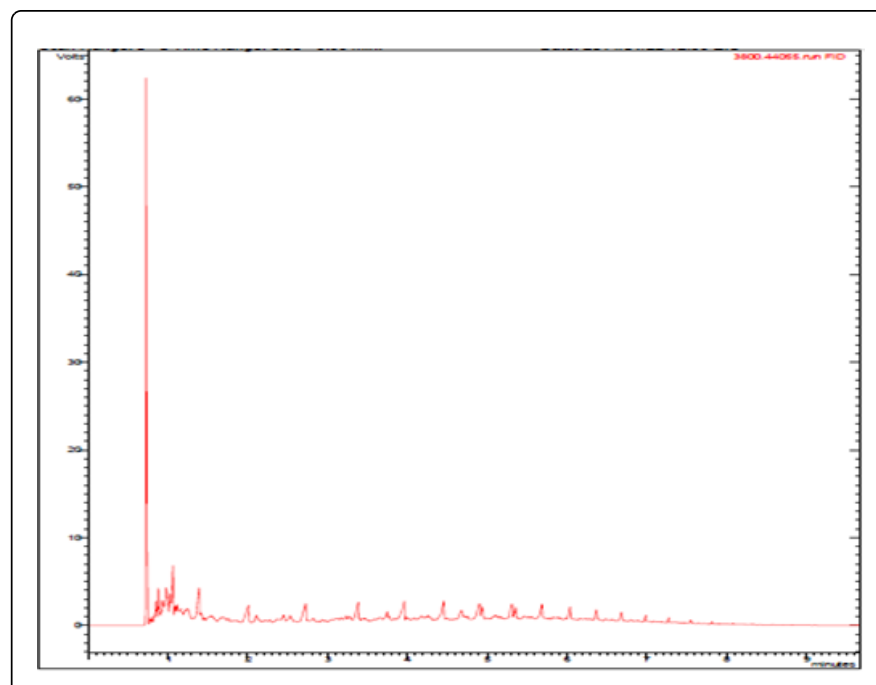

Figure 3: GC chromatogram for the gasoil before addition to the soil. 
Citation: Bahmani F, Ataei SA, Mikaili MA (2018) The Effect of Moisture Content Variation on the Bioremediation of Hydrocarbon Contaminated Soils: Modeling and Experimental Investigation. J Environ Anal Chem 5: 236. doi:10.4172/2380-2391.1000236

Page 4 of 6

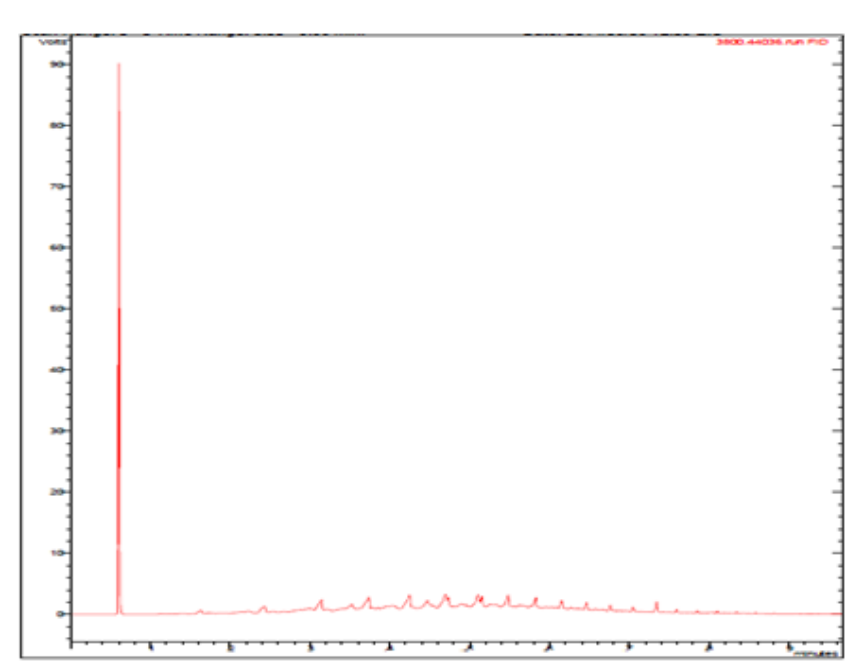

Figure 4: GC chromatogram for the extracted TPH from soil at the beginning of the process.

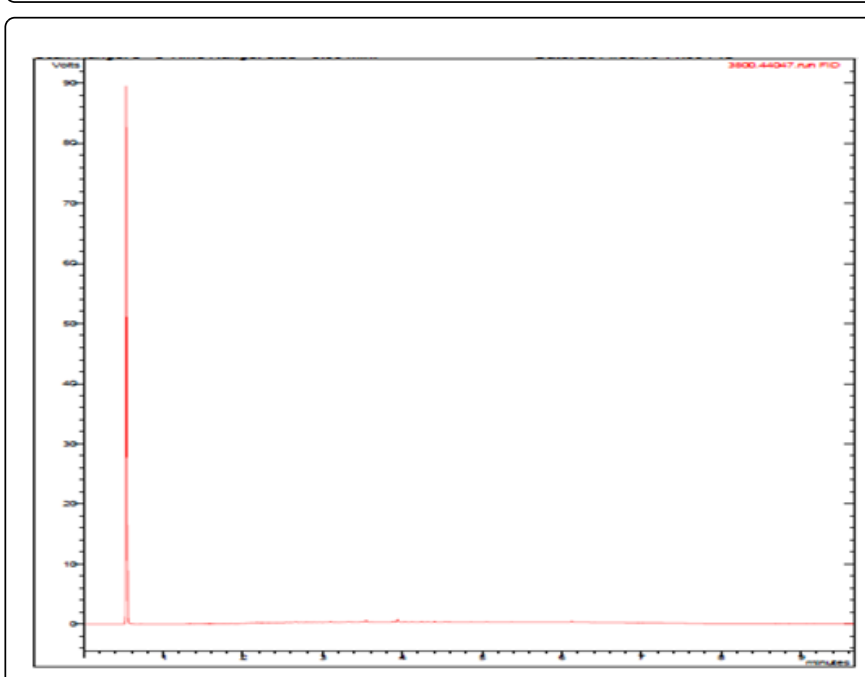

Figure 5: GC chromatogram for the extracted TPH from P1 after three months.

Figure 7 shows the results of model calibration for the determination of $\mathrm{k}_{\mathrm{B}}$ using the experimental data of the beaker with 12day water restoration intervals. The value of 0.0059 day $^{-1}$ gave minimum deviations of the experimental results and model predictions $[15,16]$. The calibrated model was used to simulate the bioremediation in the beaker with 2-day water restoration interval. Figure 8 shows the results which indicate reasonable accuracy of the model to predict bioremediation in soil. The model can also simulate the variation in water content during the process. Figures 9 and 10 show the experimental data and model simulation for water content in two of the beakers (P1 and P4).

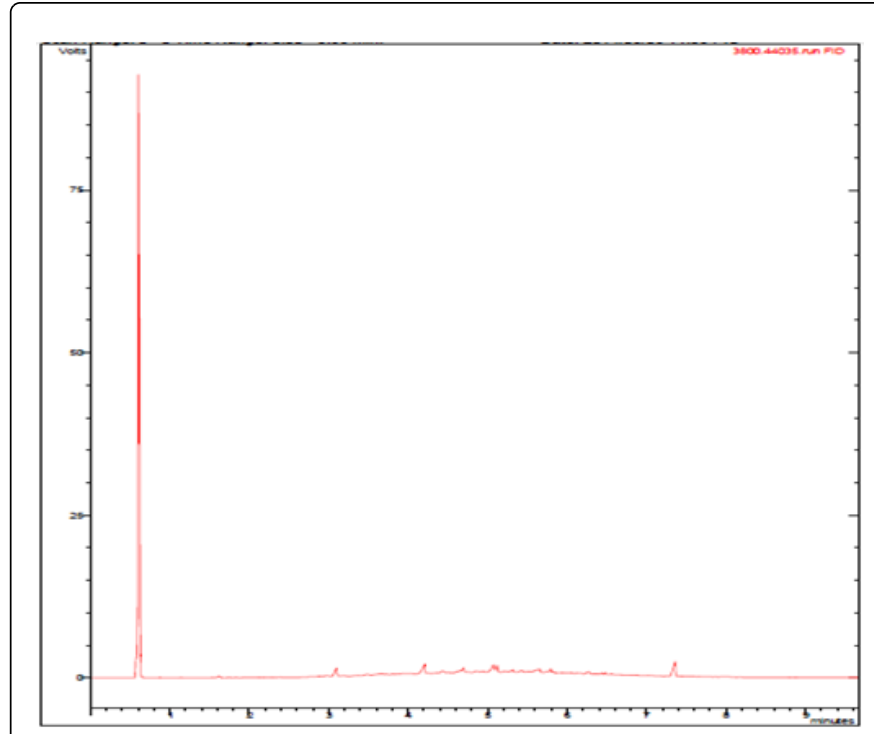

Figure 6: GC chromatogram for the extracted TPH from P4 after three months.

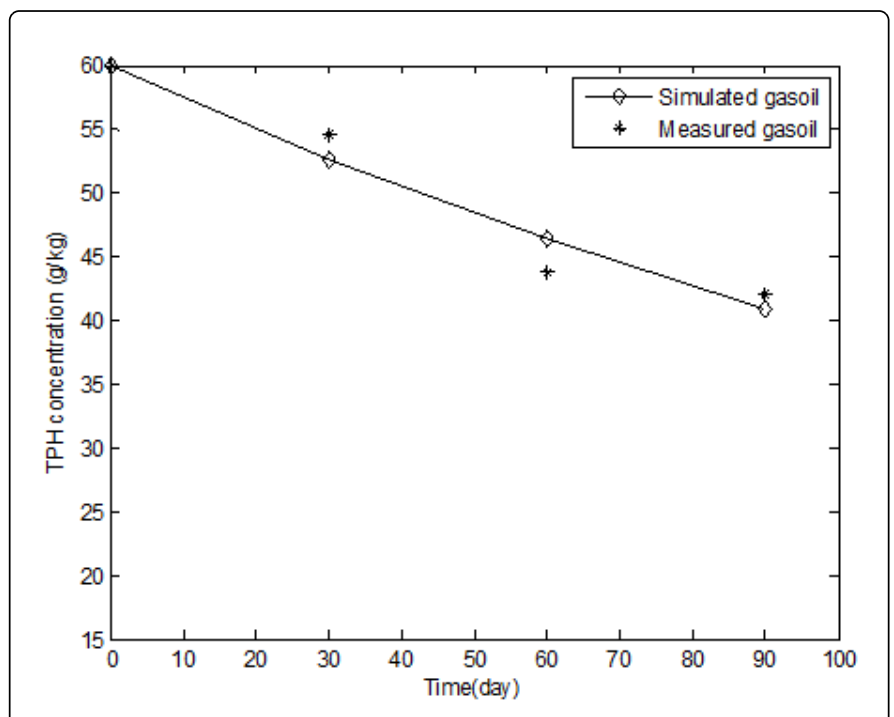

Figure 7: Comparison of model predictions (lines) with the experimental data (symbols) for the beaker P4 (water adjustment in 12 day intervals). 


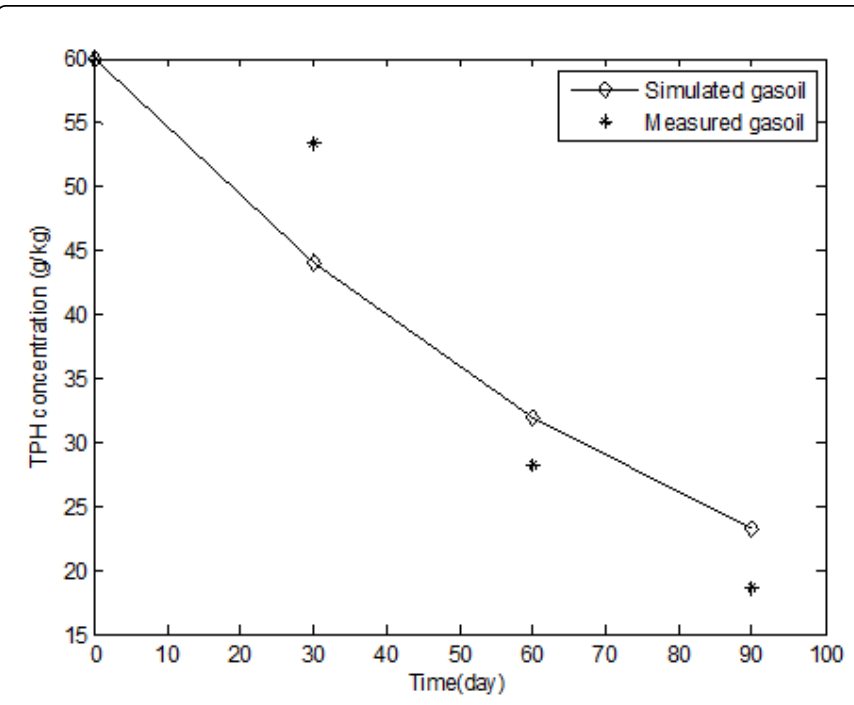

Figure 8: Comparison of model predictions (lines) with the experimental data (symbols) for the beaker P1 (water adjustment in 2 day intervals).

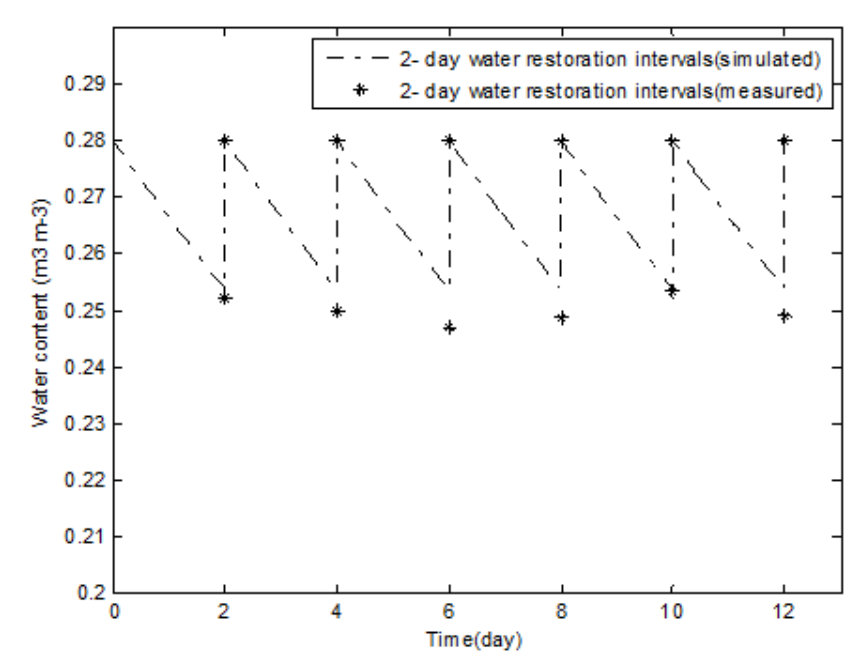

Figure 9: Model predictions for water content variation with the experimental data in beaker P1 (water adjustment in two day intervals).

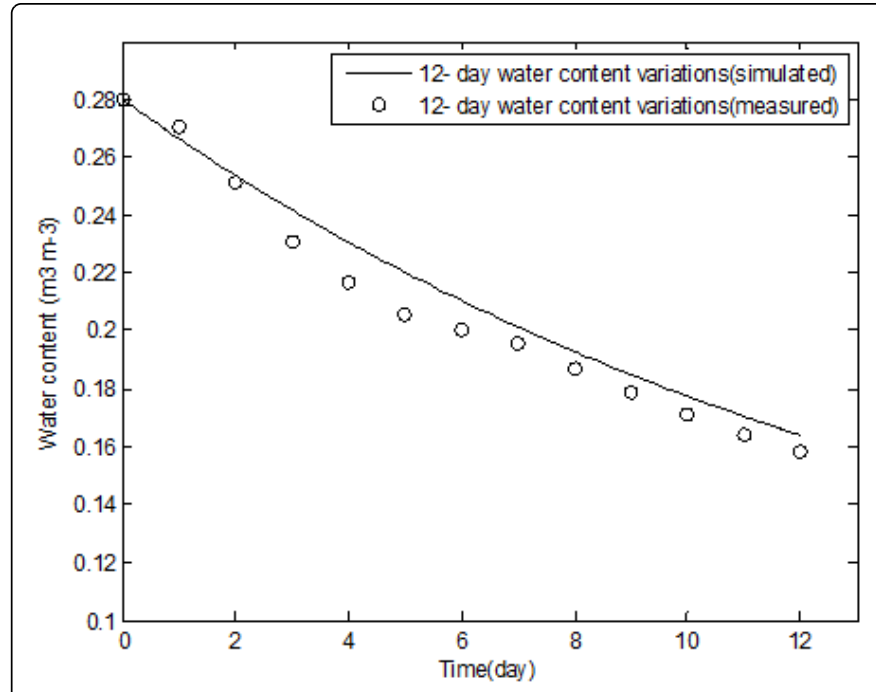

Figure 10: Model predictions for water content variation with the experimental data in beaker P4 (water adjustment in 12 day intervals).

\section{Conclusion}

From this research work it was concluded that keeping the moisture content of soil at an optimum value is critically important for a successful bioremediation process. Evaporation of water may be compensated by intermittent addition of water to the soil during bioremediation. The time interval between water additions affects the performance of the bioremediation process. The results of this study showed that adjusting the water content of a sandy clay soil to $60 \%$ of its field capacity, and moisture adjustment in two day intervals is a proper strategy to bioremediate the contaminated soil. It was also concluded that the process of bioremediation in soil can be described by a mechanistic model that incorporates a first order biodegradation rate, a model for water evaporation from the soil, and an empirical relation that accounts for the effect of moisture content on the rate of biodegradation.

\section{Acknowledgements}

The first author would like to thank National Iranian Oil Products Distribution Company (NIOPDC) of Kerman for financial assistance. Cooperation and scientific aids provided by the Biotechnology Department, Shahid Bahonar University are sincerely acknowledged.

\section{References}

1. Zawierucha I, Malina G (2006) Bioaugmentation as a method of biodegradation enhancement in oil hydrocarbons contaminated soil. Ecohydrology and Hydrobiology 6: 163-169.

2. Hesnawi RM, Adbeib MM (2013) Effect of nutrient source on indigenous biodegradation of diesel fuel contaminated soil. APCBEE Procedia 5: 557-561.

3. Bento FM, Camargo FAO, Okeke BC, Frankenberger WT (2005) Comparative bioremediation of soils contaminated with diesel oil by natural attenuation, biostimulation and bioaugmentation. Bioresource Technology 96: 1049-1055.

4. Chemlal R, Tassist A, Drouiche M, Lounici H, Drouiche N, et al. (2012) Microbiological aspects study of bioremediation of diesel-contaminated 
Citation: Bahmani F, Ataei SA, Mikaili MA (2018) The Effect of Moisture Content Variation on the Bioremediation of Hydrocarbon Contaminated Soils: Modeling and Experimental Investigation. J Environ Anal Chem 5: 236. doi:10.4172/2380-2391.1000236

Page 6 of 6

soils by biopile technique. International Biodeterioration \& Biodegradation 75: 201-206.

5. Wang ZY, Xu Y, Wang HY, Zhao J, Gao DM, et al. (2012) Biodegradation of crude oil in contaminated soils by free and immobilized microorganisms. Pedosphere 22: 717-725.

6. Skopp J, Jawson MD, Doran JW (1990) Steady-state aerobic microbial activity as a function of soil water content. Soil Sci Soc Am J 54: 1619-1625.

7. Molina-Barahona L, Rodr'iguez-Vázquez R, Hernández-Velasco $\mathrm{M}$, Vega-Jarqu' in C, Zapata-Pérez O, et al. (2004) Diesel removal from contaminated soils by biostimulation and supplementation with crop residues. Applied Soil Ecology 27: 165-175.

8. Bittelli M, Campbell GS, Tomei F (2015) Soil physics with python transport in the soil-plant-atmosphere system. Oxford University Press.

9. Scherrer P, Mille G (1990) Biodegradation of crude oil in experimentallypolluted clayey and sandy mangrove soils. Oil \& Chemical Pollution 6: 163-176.

10. Chang W, Akbari A, Snelgrove J, Frigon D, Ghoshal S (2013) Biodegradation of petroleum hydrocarbons in contaminated clayey soils from a sub-arctic site: The role of aggregate size and microstructure. Chemosphere 91: 1620-1626.
11. Chemlal R, Abdi N, Lounici H, Drouiche N, Pauss A, et al. (2013) Modeling and qualitative study of diesel biodegradation using biopile process in sandy soil. International Biodeterioration \& Biodegradation 78: 43-48.

12. Gogoi BK, Dutta NN, Goswami P, Krishna Mohan TR (2002) A case study of bioremediation of petroleum-hydrocarbon contaminated soil at a crude oil spill site. Advances in Environmental Research 7: 767-782.

13. Mariano AP, Kataoka APAG, Angelis DF, Bonotto DM (2007) Laboratory study on the bioremediation of diesel oil contaminated soil from a petrol station. Microbiology 38: 346-353.

14. Rahman KSM, Thahira-Rahman J, Lakshmanaperumalsamy P, Banat IM (2004) Towards efficient crude oil degradation by a mixed bacterial consortium. Bioresource Technology 85: 257-261.

15. Schjønning P, Thomsen IK, Petersen SO, Kristensen K, Christensen TB (2011) Relating soil microbial activity to water content and tillageinduced differences in soil structure. Geoderma 163: 256-264.

16. Suja F, Rahim F, Taha MR, Hambali N, Razali MR, et al. (2014) Effects of local microbial bioaugmentation and biostimulation on the bioremediation of total petroleum hydrocarbons (TPH) in crude oil contaminated soil based on laboratory and field observations. International Biodeterioration \& Biodegradation 90: 115-122. 